
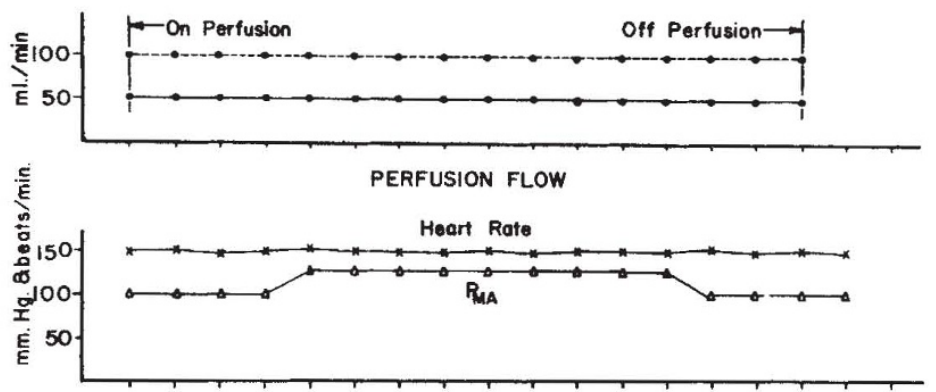

CARDIOVASCULAR RESPONSE

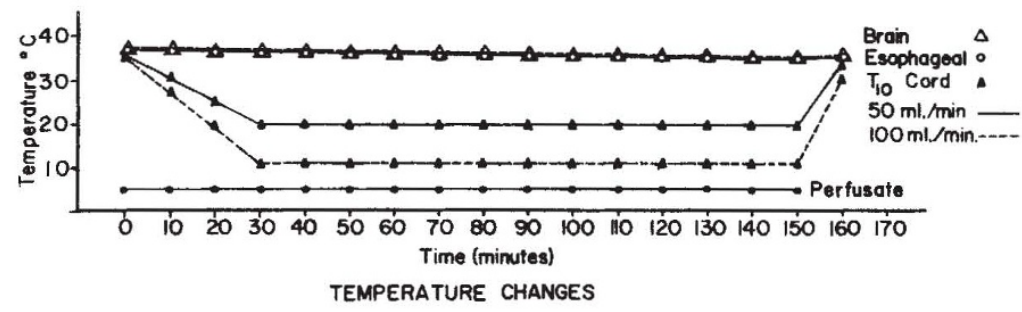

Fig. 2. Temperature changes, perfusion flows and cardiovascular responses during localized spinal cord hypothermia

near normothermic levels during perfusion. Within 10 min after termination of perfusion, spinal cord temperature in both groups returned to the pre-perfusion levels. In all animals, pulse rates remained stable during perfusion cooling and the electrocardiogram showed no abnormal changes. In both groups, the moan arterial blood pressure remained at the baseline level of $100 \mathrm{~mm}$ of mercury during the first $30 \mathrm{~min}$ of cooling, rose to and was sustained at $120 \mathrm{~mm}$ of mercury for $1.5 \mathrm{~h}$ and then returned to baseline. Electrocortical brain activity of the frontal, parietal and occipital areas monitored throughout the cooling period revealed no abnormal changes in wave forms in any of the animals during cooling.

In chronic experiments using a sterile technique, the spinal cord of five additional animals were perfusion cooled for $2.5 \mathrm{~h}$ at a flowrate of $100 \mathrm{ml} . / \mathrm{min}$, after which the surgical incision was closed and the animals were returned to their cages. No functional or neurological abnormality could be detected in any of the animals so cooled after repeated nourological examinations over a period of 2 weeks.

This work was supported by a grant from the National Institutes of Health.

MaUrice S. Albin

ROBERT J. WHITE

George E. Locke

HENRY E. KRETCHMER

Cleveland Metropolitan General Hospital and

Western Reserve University School of Medicine, Cleveland, Ohio.

${ }^{1}$ Rehder, K., Kirklin, J. W., MacCarty, C. S., and Theyc, R. A., Ann. Surg., $156,882(1962)$

${ }^{2}$ White, R. J., Albin, M. S., Verdura, J., Massopust, jun., L., and Meder, R., Proc. Seventeenth Ann. ('onf. Engin. Med. Biol., 6, 85 (1964).

${ }^{3}$ White, R. J., Albin, M. S., Verdura, J., Massopust, jun., I., and Meder, R., Clin. Res., 13, 224 (1965).

\section{Cyclic Activity in the Male Hypothalamus}

IT is well known that the administration of testosterono to fomale rats shortly after birth induces the differentiation of an acyclic male type of hypothalamus, resulting in permanent sterility and cystic ovaries lacking in corpora

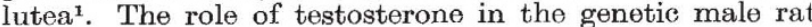
has been examined by the method of castration during infancy ${ }^{2,3}$. The findings have shown that deprivation of endogenous testosterone within 3 days of birth is followed by the differentiation of a cyclic female type of hypothalamus as seon by the presence of corpora lutea in ovarian transplants made during adult life. Castration more than 3 days after birth does not prevent the differentiation of the male type of hypothalamus, for ovaries grafted into animals so treated contained no corpora lutea in adulthood. These and other investigations ${ }^{4}$ raised the possibility that the findings would be different if the transplantation and examination of the ovaries were carried out in the immature animal.

In the present experiments male rats were castrated either less than $20 \mathrm{~h}$ after birth or when 5-6 days old. All animals received at the time of castration an abdominal transplant of a whole ovary, containing no ripe follicles or corpora lutea, from a littermate. The animals wore killed at times varying from 34 to 117 days after operation and the ovarian. transplants serially sectioned and examined for eorpora lutea. The lattor were carofully searched for entrapped ova but none was found.

All three animals castrated at 5-6 days from birth and killed when 114-122 days old showed transplants containing only well-developed follicles and no corpora lutea. thus confirming previous findings ${ }^{2,3}$. The two animals that were castrated on the day of birth and killed at 72 days of age had transplants containing ripe follicles and fresh corpora lutea, again in agreement with the observations of previous workers 2,3 . A new finding was that in all seven male rats castrated 5-6 days after birth and killed at between 39 and 61 days of age the ovarian transplants contained several fresh corpora lutea as well as ripe follicles.

The presence of the testis (and physiological amounts of testosterone) during the critical 1-3 days after birth did not therefore prevent ovarian cycles during the first 8 weeks of life, but induced lack of ovulation in adulthood. Hence it may be inferred that the genetic, intact male hypothalamus behaves in a cyclic female manner for some weeks after birth and then loses its cyelicity and functions in the stable male manner. It has been reported ${ }^{4}$ that female rats treated with testosterone shortly after birth exhibit ovarian cycles for a few weeks before doveloping the acyclic "early androgen syndrome". It would appear, then, that all hypothalami are of the female type during a significant part of the life-span and that the action of androgen, natural or pharmacological, in the neonatal period does not take effect until some time after puberty.

\section{H. J. Campbelt}

Institute of Psychiatry,

Maudsley Hospital,

Denmark Hill, London.

${ }^{1}$ Jacobsohn, D., Acta Univ. Lund., Sect. 2, No. 17 (1965).

${ }^{2}$ Harris, G. W., Endocrinology, 75, 627 (1964).

${ }^{3}$ Yazaki, I., Ann. Zool. Jap., 33, 217 (1960).

4 Swanson, H. E., and van der Werff ten Bosch, J. J., Acta Endocrinol., 47, 37 (1964).

\section{Changes in the Nervous System of Rabbits following the Administration of Sodium Diethyldithiocarbamate}

IN 1956, Můr, Zaruba and Charamza ${ }^{1}$ reported myelin degeneration in twenty-one rabbits, of which sixteen had roceived repeated intravenous injections of $\alpha$-benzoin oxime, and five had received repeated intravenous injections of diethyldithiocarbamate. The lesion, which was most marked in the spinal cord, was compared to that seen in swayback in lambs and disseminated sclorosis in man. They also reported a decrease in blood copper levels in nine out of twelve rabbits after intravenous admini- 